\title{
Desalination of salty water using vacuum spray dryer driven by solar energy
}

Ihsan Hamawand ${ }^{1 *}$, Larry Lewis ${ }^{2}$, Noreddine Ghaffour $^{3}$

${ }^{1}$ National Centre for Engineering in Agriculture (NCEA), University of Southern Queensland, Toowoomba 4350 QLD, Australia 2larrylewisnotge@gmail.com, Scotia, NY USA

${ }^{3}$ King Abdullah University of Science and Technology (KAUST), Water Desalination and Reuse Center (WDRC), Biological and Environmental Sciences \& Engineering Division (BESE), Thuwal, 23955-6900, Saudi Arabia (noreddine.ghaffour@kaust.edu.sa)

Corresponding Author: Ihsan Hamawand (Email: Ihsan.hamawand@ usq.edu.au), Tel: +61 (0) 466897659.

\section{Abstract}

This paper addresses evaporation under vacuum condition with the aid from solar energy and the recovered waste heat from the vacuum pump. It is a preliminary attempt to design an innovative solar-based evaporation system under vacuum. The design details, equipment required, theoretical background and work methodology are covered in this article. Theoretically, based on the energy provided by the sun during the day, the production rate of pure water can be around $15 \mathrm{~kg} / \mathrm{m}^{2} / \mathrm{day}$. Assumptions were made for the worst case scenario where only $30 \%$ of the latent heat of evaporation is recycled and the ability of the dark droplet to absorb sun energy is around $50 \%$. Both the waste heat from the pump and the heat collected from the photovoltaic (PV) panels are proposed to raise the temperature of the inlet water to the system to its boiling point at the selected reduced pressure.

Keyword: vacuum; evaporation; solar energy; waste heat; desalination

\section{Introduction}

Water and energy are necessary for life on Earth and to sustain the modern world. In many parts of the world, the control and exploitation of water and energy has driven economic development. In many other places there are shortages in fresh water and energy supplies. Drinking water of acceptable quality has become a scarce commodity not to mention unevenly distributed geographically worldwide [Mohammed, 2011; Hamawand and Lewis, 2016]. The World Health Organization (WHO) has estimated that lack access to drinking water may be 
an issue for more than a billion people [WHO, 2016]. The vast majority of these people are 34 from undeveloped countries and/or living in rural areas where there is low population density. In remote locations it is very difficult and costly to install traditional clean water solutions [Qiblawey \& Banat, 2008]. In many countries where there are shortages of clean and fresh water, 37 there are many other water resources that have potential to be transformed. Such resources seawater, ground water, and coal seam gas water [Hamawand et al., 2013]. These kinds of water require an innovative technique of treatment that uses sustainable and low cost energy to produce clean water.

Desalination of salty water is known to be one of the most sustainable alternative solutions to provide fresh water. This resource can play a significant role in socioeconomic development in many developing countries such as Africa, Pacific Asia and countries in the Middle East [El Kharraz et al., 2012]. Desalination is a process in which saline water is separated into two parts: one that has a low concentration of dissolved salts (fresh water), and the other which has a much higher concentration of dissolved salts than the original feed water (brine concentrate) [Buros, 2000]. Reverse Osmosis (RO) produces brine (70-55\% of intake flow) depending of feed water quality, the brine concentration varies from 50 to $75 \mathrm{~g} / \mathrm{L}$ and has a much higher density than seawater [Hamawand et al., 2013]. Desalination of salty water/seawater is expensive, mostly because of the energy required [Ghaffour et al., 2013]. However, desalination is a growing field around the world where the needs for drinkable water are crucial [Ayhan and Al Madani, 2010]. All conventional seawater desalination techniques such as RO, thermal distillation such as multi stage flash (MSF), electro-dialysis, or their combinations consume a large amount of energy and they do not recover the salt eventually. These techniques may also cause air pollution due to the large consumption of energy derived from fossil fuels [Ghaffour et al., 2014]. Furthermore, the brine remains from these processes are huge and represent another potential environmental problem [Lattemann, 2010]. There is a potential for using algae to clean the water after amending it with some chemicals, however this has not been carried out experimentally [Hamawand et al., 2014]. Therefore, the utilization of renewable energy can be considered as one of energy sources of seawater desalination [Gude and Nirmalakhandan, 2009; Bauschlicher and Wohlk, 1983; Ghaffour et al., 2013].

A complete separation of salt from salty water is something that cannot be achieved by many of the conventional methods. One conventional, most efficient and reliable method for complete 
separation is evaporation. Evaporation of water at atmospheric pressure requires large amounts of energy to raise the water temperature to the boiling point. In addition, at atmospheric pressure the evaporation rate is slow unless larger heat is supplied. This problem can be overcome by carrying out the evaporation under reduced pressure where water can be evaporated at temperatures below its atmospheric pressure boiling point. Water evaporation under reduced pressure is energy efficient according to the laws of thermodynamics, and can be driven by low-grade thermal energy sources such as solar energy or process waste heat. While the evaporation under reduced pressure will accelerate the evaporation rate, one must be concerned with potential freezing problems [Tatemoto and Miyazawa, 2011]. Heat is required for water droplets to evaporate, heat is provided from the surrounding. Without supplemental heat there is a risk that the equipment parts get chilled and the remaining droplets freeze [Kanegsberg and Kanegsberg, 2011]. Valuable information on desalination of seawater using solar energy has been reported, however,

the desalination of sea water using vacuum spray dryer has not been fully elucidated. This study presents an innovative design for evaporation of water using renewable energy from the sun and recycles the latent heat of evaporation. Also the waste heat from the pumps and collected heat from PV panels that provide the pump with electricity are suggested as another source of energy [Thu, et al. 2013; Gude, 2015].

81

\section{2}

\section{Theory}

Water such as concentrated salty water produced from other desalination processes such as RO process can be sprayed inside a double walled glass column (evaporation column) exposed to sun light, Figure 1. The double walled column will retain the heat inside the column and allow a full exposure to sun light. The column will be operated under reduced pressure to lower the water boiling point temperature. The generated vapour will condense on the chilled column (condensation column) attached to the double glassing evaporation column as shown in Figure 1. This will allow the recovery of the energy (latent heat of evaporation) used to evaporate the water. After evaporating the water, the salt will end up at the bottom of the double walled column as pure dry salt.

A dark water soluble dye will be dissolved in the salty water before being introduced to the system to enhance its absorption of the sun light. Reflected or absorbed sunlight by an aerosol depends primarily on the composition and colour of the particles dissolved in it. In general, bright-coloured/ 
translucent particles tend to reflect radiation in all directions and darker aerosols can absorb significant amounts of light [NASA, 2016]. Dark blue to black surfaces can absorb solar radiation to an approximate fraction of 0.8 to 0.9 of the incident radiation. In a study by Gary et al. (1976), they showed that dispersed carbon black dust of size less than $0.1 \mu \mathrm{m}$ can absorb solar energy as high as $5124.4 \mathrm{~J} / \mathrm{g} / \mathrm{s}\left(2 \times 10^{10} \mathrm{cal} \mathrm{Ib}^{-1}\right.$ per $\left.10 \mathrm{~h}\right)$.

The heat required for the evaporation of the water droplets can be supplied/ recovered from the following sources and sections in the process (Figure 1); sun light, double walled insulated glassing effect, black colour effect, heat generated by the vacuum pump, heat collected from the PV panels and latent heat recovered from the generated vapour. The pump can run on solar energy using solar PV cells.

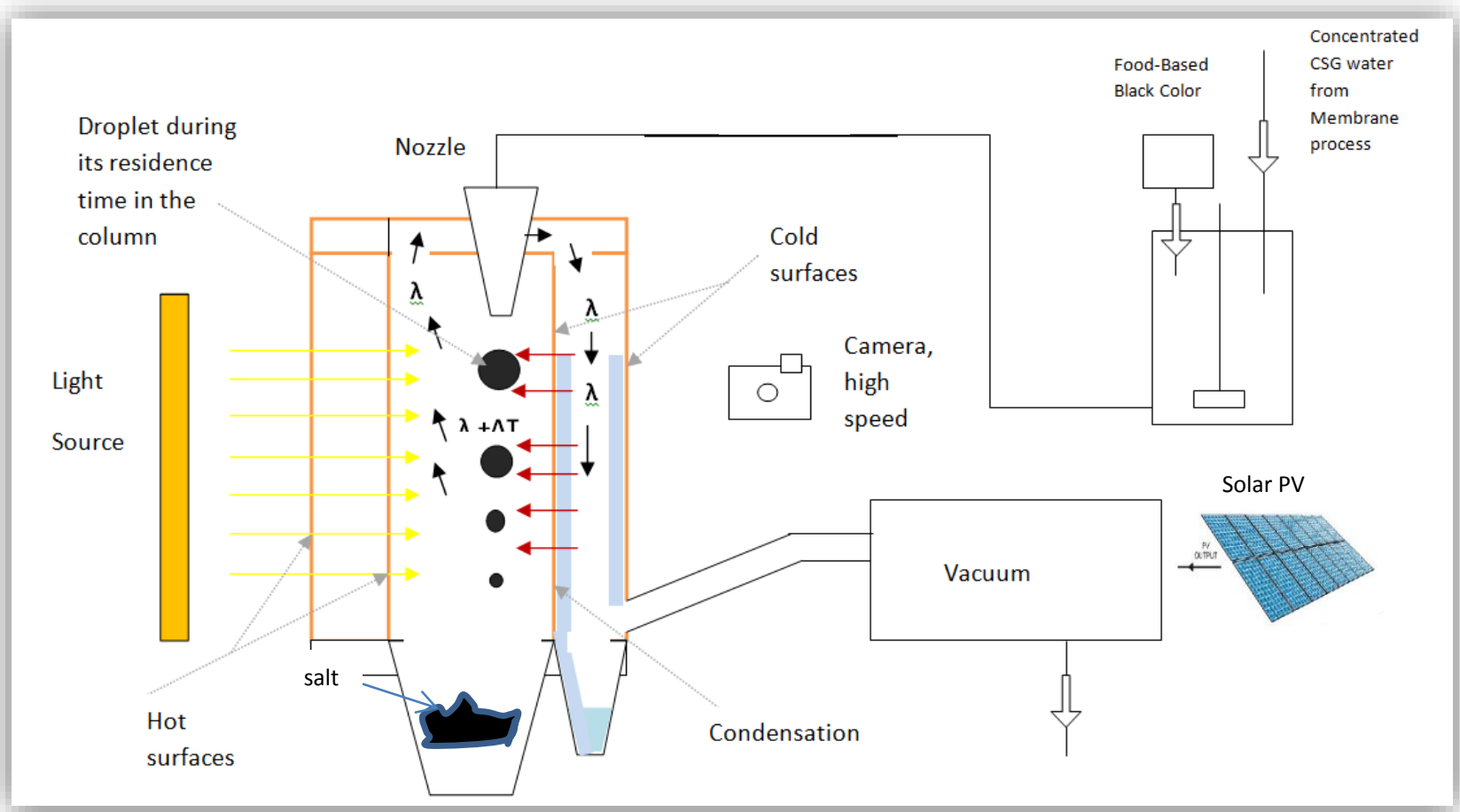

106

Figure 1: A schematic diagram of the proposed laboratory setting for the crystallization system under vacuum, double glassing column.

The evaporation process will be carried out under reduced pressure, in other words, this means that there will be a very small amount of air in the column. The water droplet will be released very close to the one of the opposite walls inside the middle column, to be specific it will be released 
113 next to the wall which is farther away from the sun light. This will create a smaller laminar sub-

114 layer at that wall and will result in a higher heat transfer coefficient in comparison to the opposite 115 wall. The fast falling of the droplet next to the wall will produce vortices (in the evaporated 116 vapour) and turbulence which lead to reduction of the laminar sub-layer thickness, Figure 2.

117 Water evaporates at a specific temperature at a specific pressure, in this design there will be three 118 zones. The first zone is the double wall glassing that faces the sun light, the pressure inside this 119 end-closed column will be above the atmospheric and the temperature is the highest among the 120 whole system because it is facing the sun light. The second zone is the middle column, the pressure 121 is below atmospheric and the temperature is almost as the same as or slightly lower than room 122 temperature (depending on the number of droplets evaporated). The lower temperature is due to 123 proximity of the vacuum pump and droplet evaporation. This zone can also be maintained at higher 124 than the droplet boiling point temperature (under vacuum) if the number of the droplets is 125 maintained in balance with the energy introduced to the system. The last zone is the vapour 126 channel, the evaporated water from the droplets in the middle column now transports to the outside 127 driven by the vacuum pump. The pressure inside this zone is the same as the middle column and 128 the temperature is the lowest among the whole system. Inside this channel condensation may 129 happen because the space available is smaller than the middle column and it is closer to the droplet. 130 The space available inside the middle column is high enough to maintain almost constant 131 temperature. The front side is exposed to sun light while, the other side of the wall where the 132 vapour is transport driven by the vacuum pump has lower space which makes the change in 133 temperature more possible, and furthermore is furthest away from the sun light. 


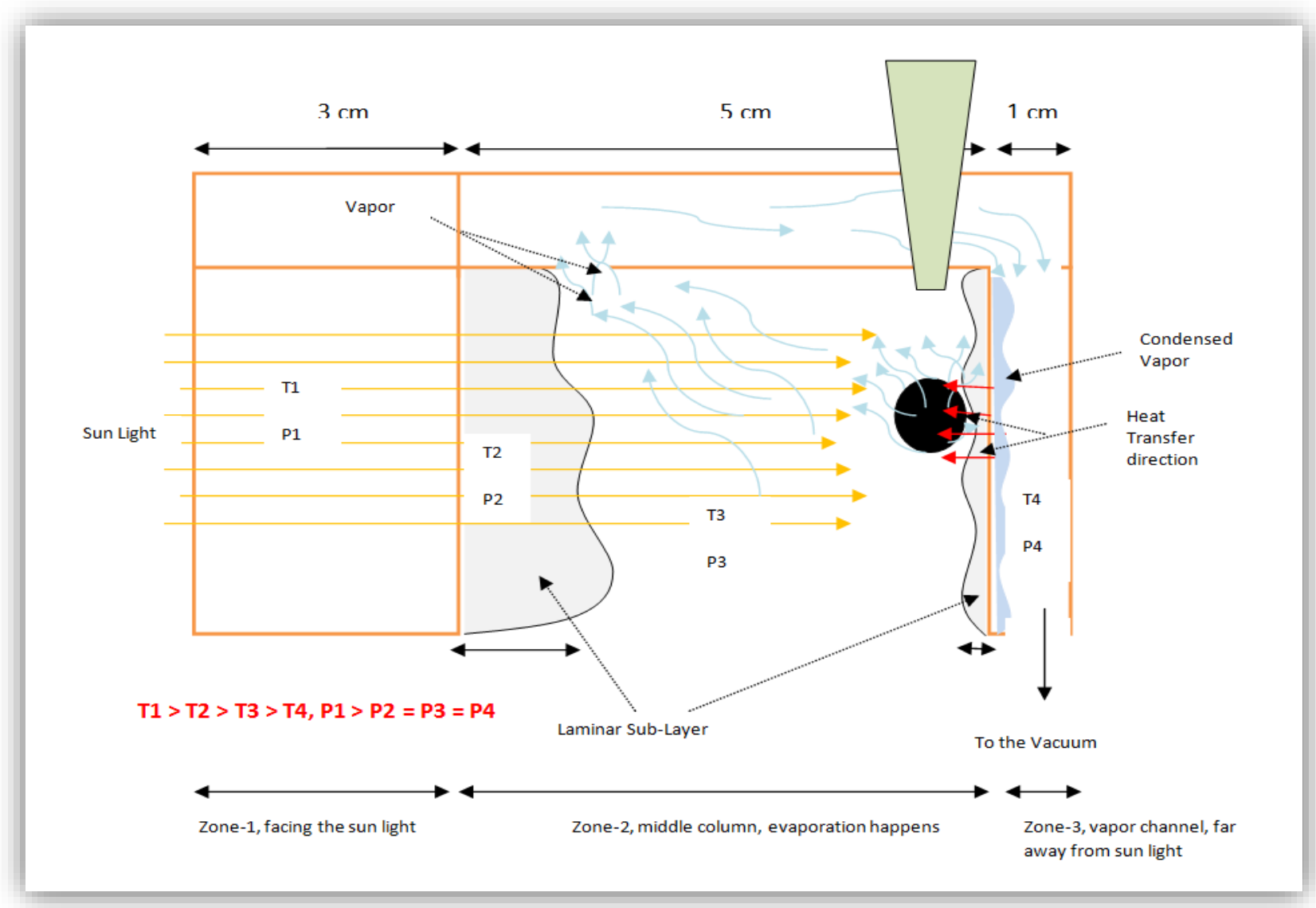

134

135

136

137

138

139

140

141

142

143

144

145

146

147

148

Figure 2: A schematic diagram of a small portion of the single column spray evaporator, theory explanation.

\section{Mathematical model}

When a free water surface is in contact with pure vapour, the equilibrium rate of molecule transfer from vapour phase to the liquid or from the liquid phase to the vapour is given by kinetic theory of gases. When the system is not at equilibrium, the net rate of evaporation or condensation per unit droplet surface area is governed by modified Hertz-Kundsen equation [Chen et al. 2000, Hamawand 2013], first proposed by Alty 1931 [Maa 1967]. Maa [1967], who studied the evaporation rate of different solvents including water. The study by Maa showed that there is little or no resistance of molecules crossing the vapour-liquid interface. This means that the evaporation coefficient is unity and can be represented by the equation (1), below, which estimates the rate of evaporation from the water droplet; 
$149-\rho_{w} \cdot \frac{d \bar{r}}{d t}=\sqrt{\frac{M_{w}}{2 \cdot \pi \cdot R_{g}}} \cdot\left[\frac{P_{\text {sat }\left(T_{d}\right)}}{\sqrt{T_{d}}}-\frac{P_{\text {med }}}{\sqrt{T_{m e d}}}\right]$

150 where,

$P_{m e d} \quad$ Is the operation pressure of the evaporation medium $(\mathrm{kPa})$,

$P_{\text {sat }\left(T_{d}\right)} \quad$ Is the saturation vapour pressure of water at droplet surface temperature $(\mathrm{kPa})$,

$M_{w} \quad$ Is the molecular weight of water $(\mathrm{kg} / \mathrm{mol})$,

$R_{g} \quad$ Is the universal gas constant (J/mol.K),

$\mathrm{T}_{\mathrm{d}} \quad$ Is the droplet temperature $(\mathrm{K})$,

$\mathrm{T}_{\text {med }} \quad$ Is the evaporation medium temperature $(\mathrm{K})$,

$\mathrm{R} \quad$ Is the droplet radius ( $\mathrm{m})$, and

$\rho_{w} \quad$ Is the water density $\left(\mathrm{kg} / \mathrm{m}^{3}\right)$.

151

152 Eq. (1) presents the rate of evaporation from the water droplet as a function of its radius (dr/dt), if 153 condensation happens then the radius of the droplet will increase otherwise it will decrease. In case 154 the droplet presented at its boiling point temperature, initial condensation, or in other words 155 increase in the droplet radius can be neglected. Not clear

156 The saturation vapour pressure of water at the droplet's surface can be given using Antoine's 157 equation (Eq. (2)) where temperature is in ${ }^{\circ} \mathrm{C}$ and pressure is in $\mathrm{kPa}$;

158

159

$\operatorname{Ln} P_{\text {sat }\left(T_{p}\right)}=16.387-3885.7 /\left(T_{d}+230.17\right)$

160 Ln refers to the natural logarithm. Using numerical method, finite deference Euler's method, 161 equations (1) and (2) can be rewritten as Eqs. (3) and (4), respectively;

$\bar{r}_{(i+1)}=\bar{r}_{(i)}-\frac{\Delta t}{\rho_{w}} \sqrt{\frac{M_{w}}{2 \cdot \pi \cdot R_{g}}} \cdot\left[\frac{P_{s a t\left(T_{d}\right)}}{\sqrt{T_{d}}}-\frac{P_{\text {med }}}{\sqrt{T_{m e d}}}\right]$ where $\bar{r}_{(i+1)}$ represents the radius of the droplet after a very small interval of time $(\Delta \mathrm{t})$ and $\bar{r}_{(i)}$ 164 represents the initial radius.

$$
\operatorname{LnP}_{\text {sat }\left(T_{d}\right)}=16.387-3885.7 /\left(T_{d}+230.17\right)
$$


167 Eqs. (3) and (4) can be used to predict the time interval required for the entire droplet to evaporate 168 and the rate the droplet evaporates. The rate of evaporation of the droplet is calculated from the 169 change in the radius of the droplet. The radius of the water receding front is an indication for the 170 amount of water evaporated from the droplet's surface.

171 These equations assume that the droplet is entering the system at the temperature of evaporation 172 (depending on the system's pressure) which means neglecting initial condensation is applicable.

173 By introducing the waste heat from the vacuum pump, recycled latent heat of evaporation and heat 174 collected from the PV panels, it is possible to introduce the droplet to the system at its boiling 175 point. The temperature of the droplet will remain constant at its boiling point due to continuous 176 evaporation while provided with sufficient heat. Also, the saturation vapour pressure of the water 177 droplet will be constant based on Eq. (4). Furthermore, the vacuum pump is assumed to be efficient 178 and is able to keep the pressure inside the system constant.

179 The evaporation will be dominated by the heat transfer from the medium (mostly vapour) to the 180 droplet plus that received directly from the sum via radiation. For simplicity, at steady state 181 conditions, the medium (wrong word?) receive energy from the sun and is transferred to the 182 droplet, the temperature of the medium is assumed to be constant and slightly above the droplet 183 temperature due to losing its heat to the droplet via convection. Based on this assumption, the 184 amount of water evaporated is calculated to maintain these conditions in the system.

\section{Simple scenario}

187 Assume low vacuum pressure of $6.9 \mathrm{Kpa}$, this means that the droplet needs to enter the system at $188 \quad 38.7^{\circ} \mathrm{C}$ to start evaporating instantly (no initial condensation).

189 The maximum amount of energy received from the sun in ideal circumstances is $1,000 \mathrm{~W} / \mathrm{m}^{2}$. 190 Figure 3 shows the energy received from the sun per square meter on a clear day. The energy varies 191 between 100-1,000 W/m² depending on time of day. The data for the actual energy received which 192 is provided by the sun on a clear day was retrieved from a book by Stine and Geyer, (2001), Figure 1933. 


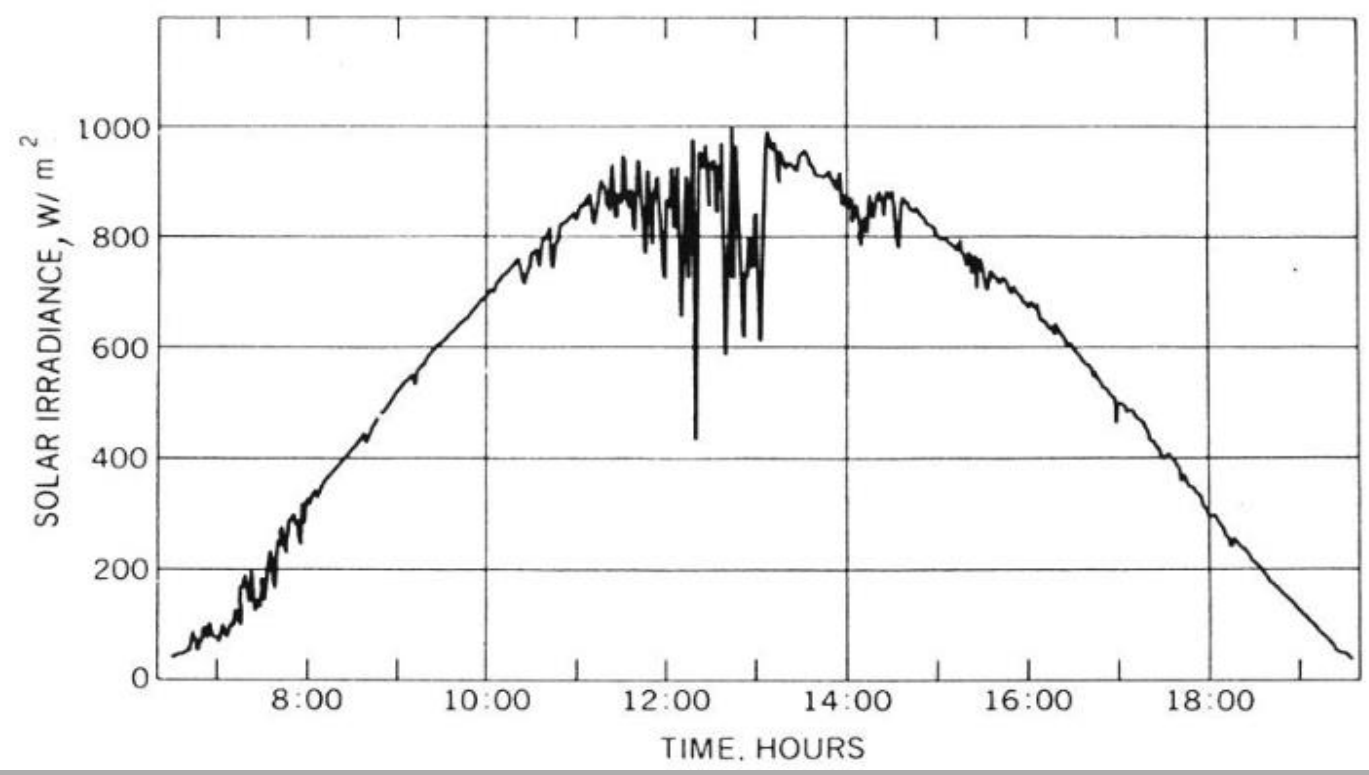

195

196

197

198

199

200

201

202

203

204

205

206

207

208

209

210

Figure 3: An example of irradiance for a mostly clear day on a horizontal surface in Greenbelt, MD (Thekaekara, 1976): global solar radiation for the day was $27.1 \mathrm{MJ} / \mathrm{m}^{2}$ [Stine and Geyer, 2001].

In this simple case, the recycled latent heat was not included in the calculation which otherwise would enhance the system efficiency. The waste heat from the pump has been assumed to provide heat for the droplet before entering the system to increase its temperature to the boiling point along with piping system connected to the solar PV panel if required. In this scenario, the system (medium, surroundings) the temperature is assumed to be constant at $38.7+5{ }^{\circ} \mathrm{C}$ (this is a reasonable assumption under clear day and direct contact with the sun light) and the extra temperature (heat) gained from the sun will be used to evaporate the droplets. For a droplet of 3 $\mathrm{mm}$ diameter ( $0.014 \mathrm{~g}$ weight), the model shows that it takes approximately $0.6 \mathrm{~s}$ to evaporate (Figure 4) the droplet. Furthermore, the height of the system required to accommodate the $0.6 \mathrm{~s}$ time required for evaporation the droplets was estimated. Based on the speed the droplet travels to reach the base of the system, $3 \mathrm{~m}$ height column is required. 


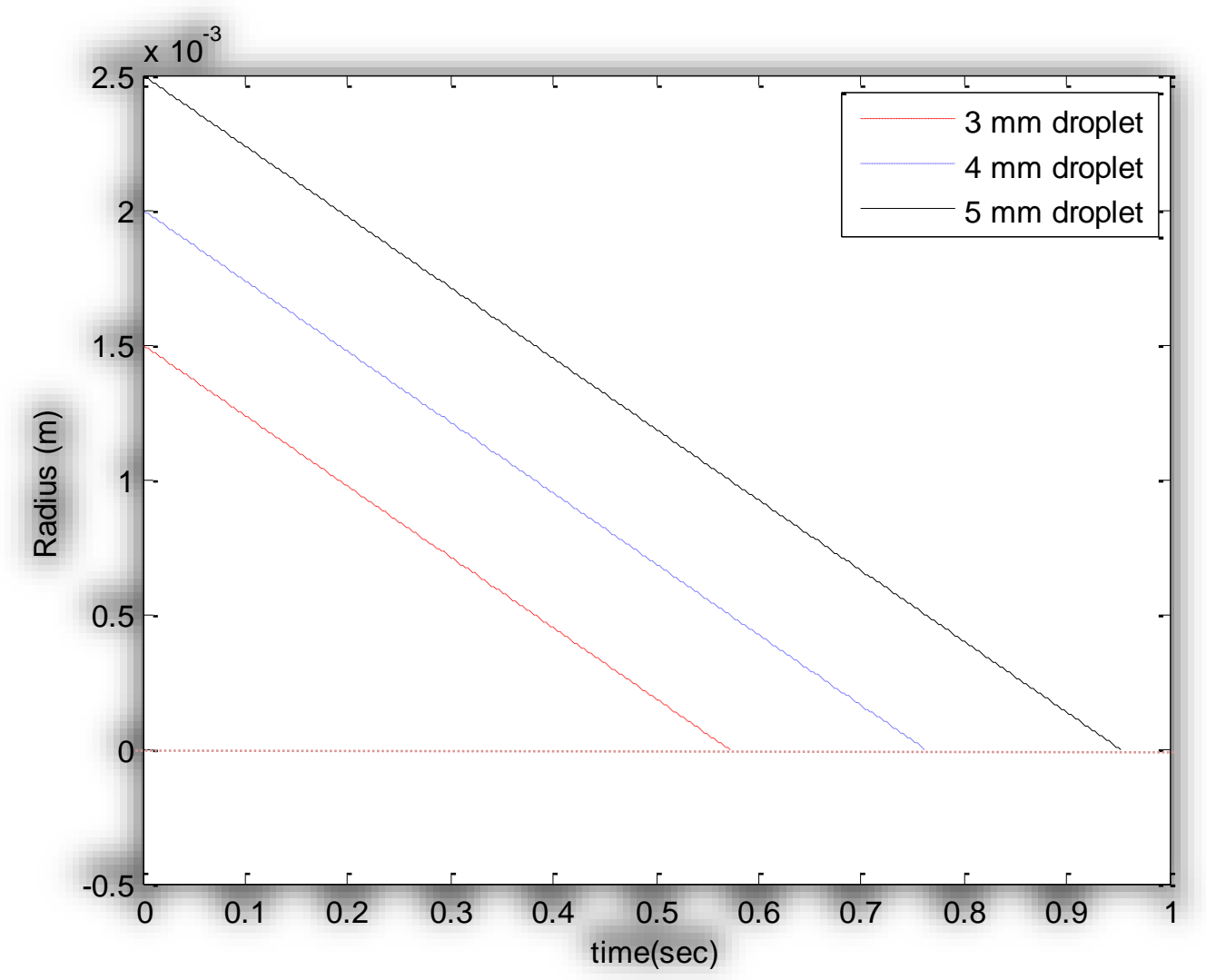

211

212

213

214

215

216

217

218

219

220

221

222

223

224

225

226

227

Figure 4: Time required for evaporating a water droplet (3, 4 and $5 \mathrm{~mm}$ diameter) under reduced pressure

The results in figure 4 means that in order to evaporate one droplet every 0.6 seconds, it is required to raise the temperature of the input water to $38.7^{\circ} \mathrm{C}$ and the temperature of the medium (mostly vapour) where the droplet travel to $38.7+5^{\circ} \mathrm{C}$. It is assumed that the initial temperature of the water and the medium is $20{ }^{\circ} \mathrm{C}$. The energy required to raise the temperature of the water to $38.7{ }^{\circ} \mathrm{C}$ is; $\mathrm{m} \times \mathrm{Cp} \times \Delta \mathrm{T}=0.00001413 \mathrm{~kg} \times 4.18 \mathrm{~kJ} / \mathrm{kg} . \mathrm{K} \times(38.7-20) \mathrm{K}=1.104 \mathrm{~J}$. As mentioned previously the calculation is for $1 \mathrm{~m}^{2}$ area exposed to sun light, in case the depth of the evaporation compartment is $0.3 \mathrm{~m}$ then the volume occupied is $0.3 \mathrm{~m}^{3}$. However, the system is under vacuum, continuous vapour is produced which also gains energy from the sun and the walls of the compartment which later transfers to the droplet. The specific heat of water vapour at $43.7{ }^{\circ} \mathrm{C}$ is $1.871 \mathrm{~kJ} / \mathrm{kg} . \mathrm{K}$ and the density at standard conditions is $0.804 \mathrm{~kg} / \mathrm{m}^{3}$. To raise the temperature of the medium to $38.7+5$ ${ }^{\circ} \mathrm{C} ; \mathrm{m} \times \mathrm{Cp} \times \Delta \mathrm{T}=(0.804 \times 0.3) \mathrm{kg} \times 1.871 \mathrm{~kJ} / \mathrm{kg} . \mathrm{K} \times((38.7+5)-20) \mathrm{K}=10.7 \mathrm{~J}$ of energy is required. The total amount of energy required to maintain the system at the condition assumed is $11.8 \mathrm{~J}$ for evaporating one droplet each 0.6 second. The sun provides an average $579 \mathrm{~J} / \mathrm{s}\left(27.1 \mathrm{MJ} / \mathrm{m}^{2} /\right.$ day 
$228(13 \mathrm{hr}))$ and the latent heat of evaporation required is $34.25 \mathrm{~J}\left(2424 \mathrm{KJ} / \mathrm{kg} \times 0.01413 \times 10^{-3} \mathrm{~kg}\right)$ for 229 each droplet each 0.6 second. Also, in 0.6 second, the water droplet mixed with dark colour is able 230 to absorb $43.4 \mathrm{~J}[5124.4 \mathrm{~J} / \mathrm{g} / \mathrm{s}$ (energy absorbed by $1 \mathrm{~g}$ black carbon) $\times 0.01413 \mathrm{~g}($ droplet mass $) \times$ $2310.6 \mathrm{~s}$ ]. This gain of energy confirms the possibility of providing the droplet with enough energy to 232 evaporate even only from the direct irradiation to the droplet. Based on the data above, the mass 233 of water can be evaporated in this system was calculated.

234 In case the droplet gets $10.7 \mathrm{~J}$ from the medium/recycled latent heat/pump waste heat and/or the 235 pipes connected to the solar system. And $23.55 \mathrm{~J}$ (53\% of the $43.4 \mathrm{~J}$ ) absorbed directly from the 236 sun, the number of droplets that can be evaporated is around 16.9 droplets (579/34.25) and the 237 amount evaporated in one day (13 hours) is $11.2 \mathrm{~kg} / \mathrm{m}^{2} /$ day $(16.9 \times 0.00001413 \mathrm{~kg} \times 13 \mathrm{~h} \times 3600$ 238 s). In case $30 \%$ of the latent heat of evaporation has been recycled then 24.15 droplets (579/ $239(34.25 \times 0.7))$ can be evaporated and total amount of $15.9 \mathrm{~kg}$ per day. Figure 5 shows the distribution 240 of the mass of water that can be evaporated per second during the day from 0600 to 2000 . The 241 maximum mass of water that can be evaporated is around $4 \mathrm{~g}$ and $6 \mathrm{~g}$ which occurs around 0100 242 (middle of the day) when the maximum energy received from the sun $\left(1000 \mathrm{~W} / \mathrm{m}^{2}\right)$ for both cases, 243 respectively.

244

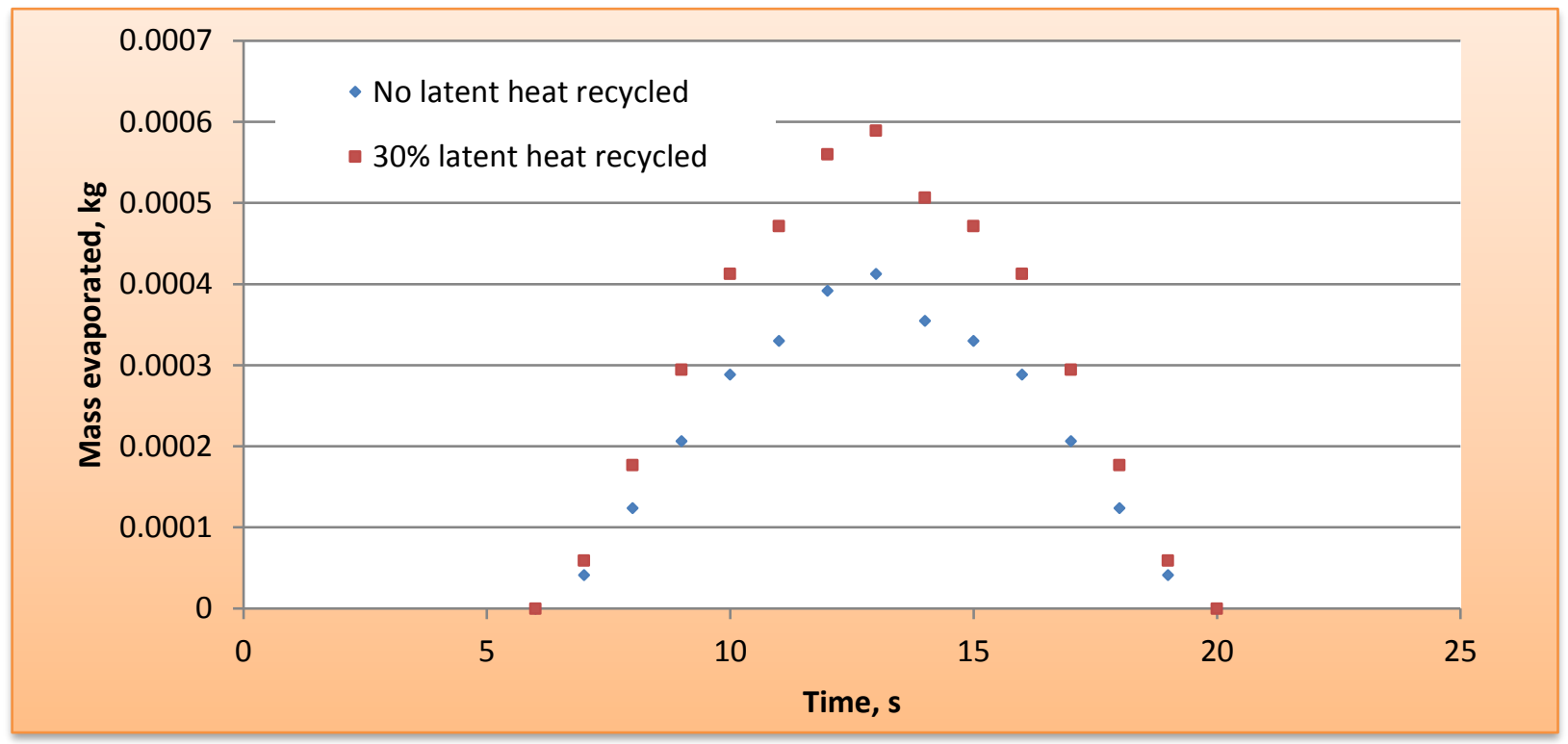

246 Figure 5: Mass of water that can be evaporated per second during different times of the day 247 without and with $30 \%$ of the latent heat recycled. 
In case the temperature of the inlet water to the system rises above $38.7^{\circ} \mathrm{C}$ and/or the temperature of the medium rises above $38.7+5{ }^{\circ} \mathrm{C}$ then the time required for evaporation will reduce, see Figure 65. A high temperature condition will not impact the amount of water evaporated because the received energy from the sun per second is the same as the previous case. It is very important then to balance the energy received from the sun (plus the recycled latent heat and waste energy) with the droplet size and the time of evaporation to avoid freezing the system.
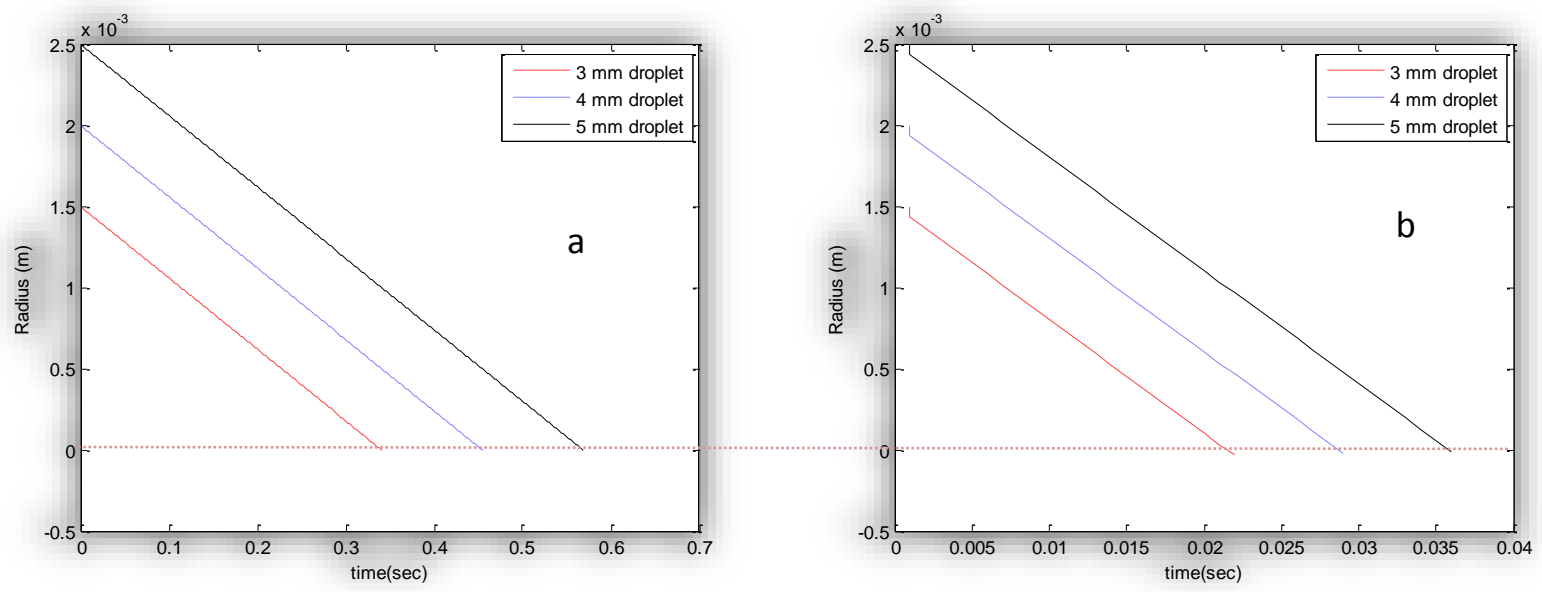

Figure 6: In the case where the: (a) temperature of the medium increased by $10{ }^{\circ} \mathrm{C}$ instead of $5{ }^{\circ} \mathrm{C}$ and droplet temperature at $38.7^{\circ} \mathrm{C}(\mathrm{b})$ and where the temperature of the droplet increased by $5{ }^{\circ} \mathrm{C}$ above boiling point and medium temperature is at $38.7^{\circ} \mathrm{C}$.

\section{Methodology, Challenges and feasibility}

\section{Methodology}

The experimental evaluation will be carried out as following;

- Empty column evaluation: estimate the heat accumulation in a one square meter area system with time.

- The water can be heated to a variety of temperatures prior to spreading in the spray column, this will help to indicate the optimum temperature of the water and at the same time help to evaluate the efficiency of using the waste heat from the vacuum pump.

- The variables that should be considered in regards to the droplet will be: size, colour, residence time, temperature and salt concentration.

- Measure the temperature inside the system at different heights and widths. 
- Wall temperatures inside and outside of the system, in addition to the outdoor temperature.

- Measure the moisture content of the solid salt produced.

\section{Sensors and equipment}

The equipment required for building a lab-scale system includes the following;

- Vacuum pump, the efficiency of vacuum pumps to maintain a constant and consistent reduce pressure is around ....

- Temperature sensors to monitor the temperature of the water inlet, outlet and the salt produced. Also the temperature inside the chamber with time.

- Thermal and high speed camera to monitor the temperature of the droplet and its diameter while traveling through the system.

- A nozzle designed to release a specific amount of droplets only when the reduced pressure is close to the boiling point of the droplet.

\section{Challenges}

- The nozzle should be very fast in spraying the droplet to avoid evaporation at its tip. This may block the nozzle either by the remaining salt after evaporation of the water or the droplet may freeze at its tip.

- Multi droplets system, it will be limited to a specific droplets number per cubic unit of space, exceeding this limit may lead to exhaustion of the heat in that specific space and may lead to freezing the entire system.

\section{Feasibility}

- For a concentrated salty water of $50 \%$ salt, the ability of water treatment will be doubled.

- For more efficient use of the sun energy the amount of water produced per day may be doubled.

- Including the recycled latent heat of evaporation, waste heat from the pump and the droplet colour effect will all contribute in enhancing the system efficiency.

Figure 7 below shows a schematic diagram of an industrial scale of the system where multi droplets are spread. Based on this design, two products can be recovered cold pure water and pure coloured salt. 


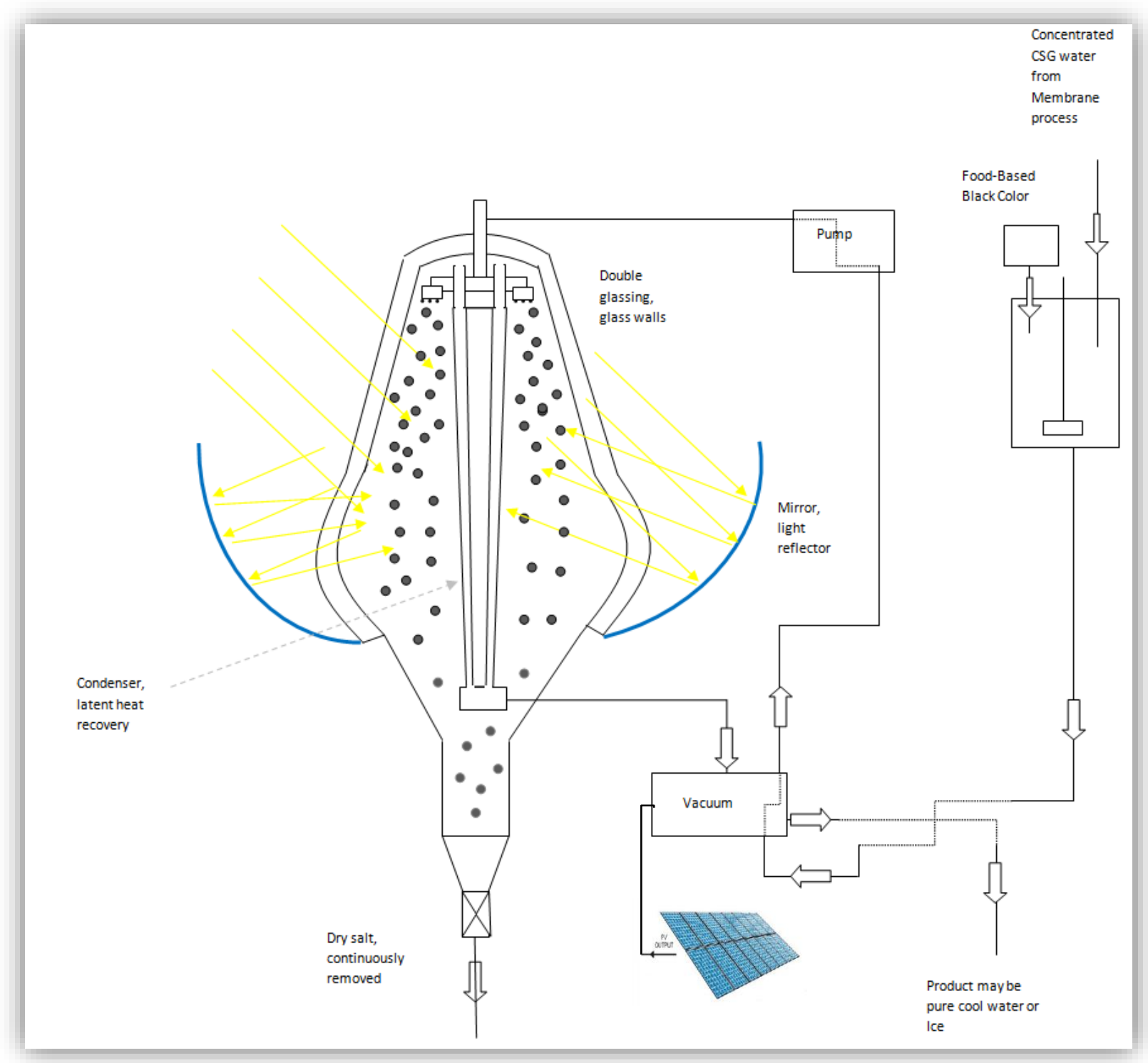

Figure 7: A schematic diagram for the proposed prototype setting for the evaporation system under vacuum, large-scale setting.

\section{Other design option}

306 The other design option is a rotating black coloured conveyer where the droplet sprayed over and 307 travels instead of traveling in the vacuum (mostly vapour). In this case the entire surface will 308 collect the energy from the sun and will be transferred to the droplet by conduction. The droplet 309 will travel from one end of the conveyer to the other end where the dry salt can be collected by 310 scraping (Figure 8). 


\section{Radiation}
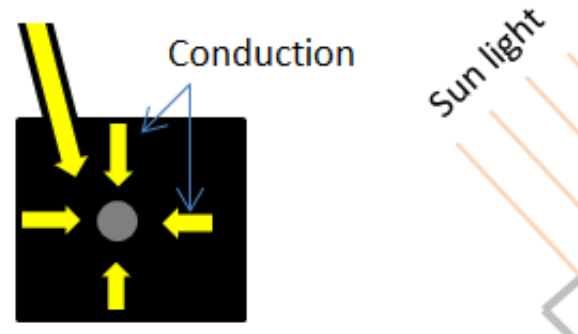

Energy received by the droplets

Dry Salt

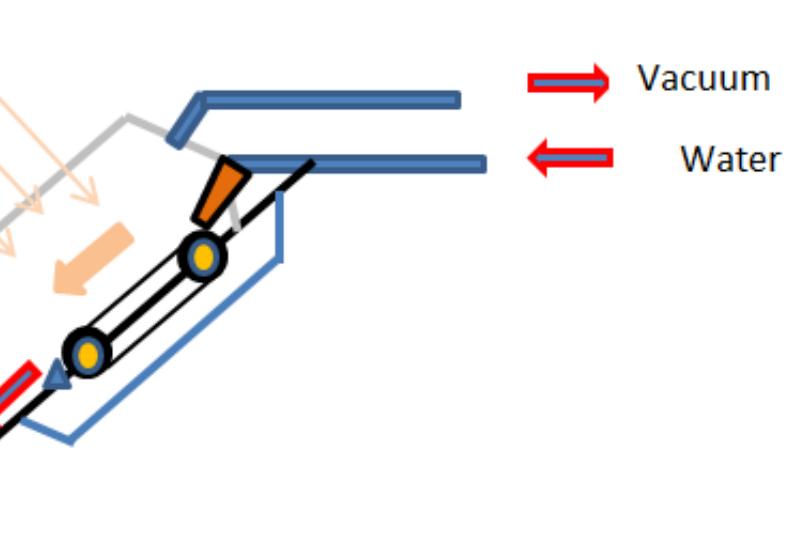

Figure 8: Another design option

\section{Innovative system for harvesting solar energy}

Another option for the design of the system is a spherical closed environment. This system can be used to trap the sun light inside the system. In case the system used for evaporation, mirrors attached to the inside of the spherical shaped system (Figure 8) are capable of reflecting the energy without losing it for more efficient energy collection and more efficient evaporation. In case the spherical system is used for collecting heat and electricity, the system should covered with PV cells, this new shape allows more exposed surface to the sun light with less footprint occupied. The solar cells are protected against the weather disturbance and make better use of the 324 light.

325 Simple calculation of the Spherical Solar Cell system;

326 The internal surface area for a sphere with Diameter of $1.0 \mathrm{~m}$

$327 \quad S . A=4 \pi r^{2}=4 \pi(0.5 m)^{2}=\pi=3.14 m^{2}$

328 Number of small hemisphere with diameter of $0.1 \mathrm{~m} \mathrm{spread}$ on $1 \mathrm{~m}$ diameter of the big entire 329 sphere (1 $\mathrm{m}$ diameter) is (each hemisphere will occupy an area equivalent to an area occupied by 330 a circle with $0.1 \mathrm{~m})$;

$$
N o=3.14 m^{2} / \pi(0.05)^{2} m^{2}=400
$$


332 Surface area created by a half sphere of $0.1 \mathrm{~m}$ diameter $=2 \pi(0.05)^{2} \mathrm{~m}^{2}=1.57 \times 10^{-2} \mathrm{~m}^{2}$

333 Surface area created by the 400 small half sphere $=400 \times 1.57 \times 10^{-2} \mathrm{~m}^{2}=6.28 \mathrm{~m}^{2}$

334 A complete closed sphere will:

- Protect the surface of the silicon cells from the weather condition

- Possibility of using a rough surface for more light absorbent, uncovered cells / very low reflection of light

- Creates $6.3 \mathrm{~m}^{2}$ for each $1 \mathrm{~m}^{2}$ of footprint

- Higher intensity of light inside the globe

- No escape of light entering the sphere

- Easy to control and direct toward the sun light

- Thermal energy production via heat exchanger placed inside the sphere (Figure 8), this also help to cool the cells.

The system includes placing a large elliptical shaped sun light collector at the top of the sphere and then focuses it to the inside of the sphere. A light spreader placed in the middle of the sphere will be required to spread the light inside the sphere space.

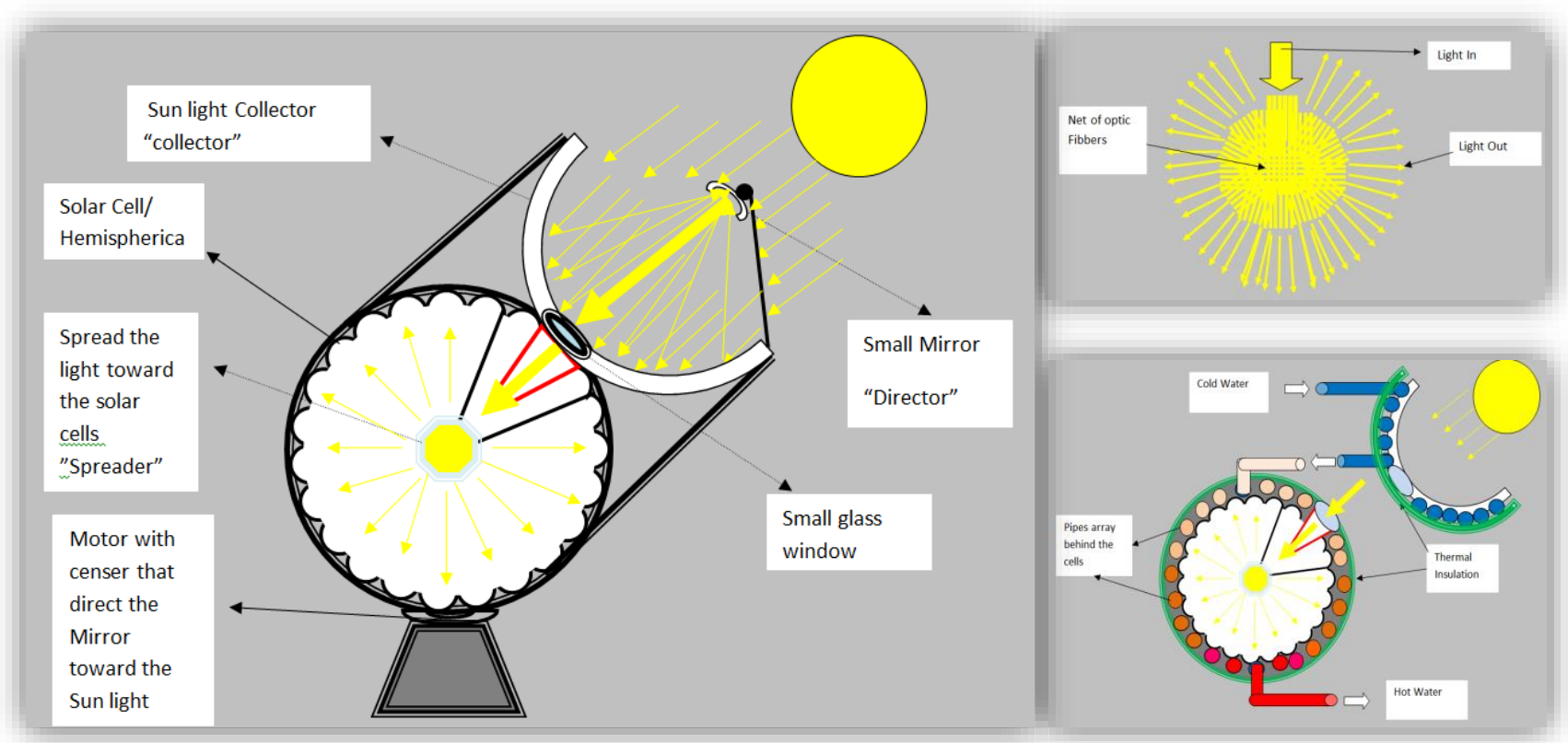

Figure 8: Spherical shape light (energy) trapping system, to the left the entire system, right top is the fibre optic spreader and the right bottom is the pipes implemented to collect the heat 350 accumulated in the system. 
352 The energy provided by the sun in a clear day (figure 7) is around $27.1 \mathrm{MJ} / \mathrm{day} / \mathrm{m}^{2}$. In case $50 \%$

353 this energy trapped in the spherical system, then the amount of water can be introduced to the 354 vacuum evaporator at $100{ }^{\circ} \mathrm{C}$ can be around $40.5 \mathrm{~kg}$ /day or this can be at lower amount but with 355 higher temperature. This water first will be circulated in the spherical system (Figure 8) to collect 356 the energy from the sun and it is based on $1 \mathrm{~m}^{2}$ surface area available for collecting the sun energy; $35727.1 \mathrm{MJ} /$ day $\times 50 \%=\mathrm{m} \times \mathrm{Cp} \times \Delta \mathrm{T}=\mathrm{m} \mathrm{kg} /$ day $\times 4.182 \mathrm{~kJ} / \mathrm{kg} / \mathrm{K} \times(100-20) \mathrm{K}=40.5 \mathrm{~kg} / \mathrm{day}$

358 This spherical collector will eliminate the initial condensation phenomena in the vacuum system 359 and at the same time provides extra energy to the vacuum system. Also, the solar panel inside the 360 sphere will provide electricity to drive the vacuum pump.

\section{Conclusions}

363 To conclude, the innovative design presented in this article shows potential of more efficient use 364 of solar energy when combined with vacuum action and waste heat/latent heat/solar heat recycling. 365 PV cells can be used to drive the vacuum pump in the system. Around $15 \mathrm{~kg} / \mathrm{m}^{2} /$ day of pure water 366 can be produced in addition to by-product salt. Spherical closed system that is capable of trapping 367 sun light will have a better efficiency than an open design to collect the heat and electricity from 368 the sun light. In the vacuum system, it is very important to keep balance between the received 369 energy from the sun, recycled latent heat, waste heat from the pump and the heat collected from 370 PV panel with the droplet size, number and speed of traveling.

\section{Acknowledgement}

373 The authors would like to thank Professor David Buttsworth (USQ/Australia) for his valuable 374 advice and help to achieve this work.

\section{References}

377 Kanegsberg, B. and Kanegsberg, E. Handbook for critical cleaning. Second edition, 2011, CRC 378 Press.

379 Ayhan, T. and Al Madani, H. Feasibility study of renewable energy powered seawater desalination 380 technology using natural vacuum technique. Renewable Energy 2010; 35: 506-514. 
381 Gude, V.G. and Nirmalakhandan, N. Desalination at low temperature and low pressure. 382 Desalination 2009; 244: 239-247.

383 Bauschlicher, H. and Wohlk, W. Production of Vacuum Salt Based on Seawater as Raw Materials. 384 Sixth International Symposium on Salt, 1983 - Vol.11.

385 Tatemoto, Y. and Miyazawa, K. Drying of Suspensions in a Fluidized Bed of Inert Particles Under 386 Reduced Pressure. Drying Technology 2011; 29: 1204-1209.

387 V. G. Gude and N. Nirmalakhandan. "Desalination at low temperatures and low pressures", 388 Desalination 244 (2009) 239-247.

389 The Engineering Tool Box, http://www.engineeringtoolbox.com/.

390 Kyaw Thu, Hideharu Yanagi, Bidyut Baran Saha' ' and Kim Choon Ng." Performance analysis of a 391 low-temperature waste heat-driven adsorption desalination prototype". International Journal of 392 Heat and Mass Transfer. Volume 65, October 2013, Pages 662.

393 Veera Gnaneswar Gude. "Energy storage for desalination processes powered by renewable energy 394 and waste heat sources", Applied Energy. Volume 137, 1 January 2015, Pages 877nced

395 Stine W B and Geyer M, 2001. Power From The Sun. Retrieved in April 2016 from 396 http://www.powerfromthesun.net/book.html

397 Hamawand, I. Drying Steps under Superheated Steam: A Review and Modeling. Energy and 398 Environment Research; Vol. 3, No. 2; 2013.

399 Hamawand I, Yusaf $\mathrm{T}$ and Bennett J. Study and modelling drying of banana slices under 400 superheated steam. Asia-Pac. J. Chem. Eng. 2014; 9: 591-603.

401 NASA. Aerosols and Incoming Sunlight (Direct Effects). Retrieved August 2016 from 402 http://earthobservatory.nasa.gov/Features/Aerosols/page3.php

403 Gary WM, Frank WM, Corrin ML and Stokes CA. Weather modification by carbon dust 404 absorption of solar energy. Journal of Applied Methodology 1976, volume 15.

405 Hamawand I and Lewis L. Innovative pit design and sludge dewatering for rural areas. Journal of 406 Environmental Chemical Engineering 2016, in press.

407

408 World Health Organization (WHO) website, http://www.who.int/en/, 2016. 409 
413 N. Ghaffour, T.M. Missimer, G.L. Amy, Technical review and evaluation of the economics of

414 water desalination: Current and future challenges for better water supply sustainability,

415 Desalination 309 (2013) 197-207.

416 Lattemann S. Development of an environ impact assessment and decision support system for

417 seawater desal plants (PhD thesis), CRC Press/Balkema, http:// repository.tudelft.nl/

$418 \mathrm{search} / \mathrm{ir} /$ ?q=lattemann\&faculty=\&department=\&type=\&year=(last accessed: 18.01.2013),

4192010.

420

421 N. Ghaffour, J. Bundschuh, H. Mahmoudi, M.F.A. Goosen, Renewable energy-driven

422 desalination technologies: A comprehensive review on challenges and potential applications of 423 integrated systems, Desalination 356 (2015) 94-114.

424

425

N. Ghaffour, S. Lattemann, T.M. Missimer, K.C. Ng, S. Sinha, G. Amy, Renewable energy-

427 driven innovative energy-efficient desalination technologies, Applied Energy 136 (2014) 1155-

Appendix

MATLAB program used to generate the data in figure 3

431

clear all

441

응 System conditions

\% vacuum pressure, medium pressure

$\mathrm{Pm}=6900 ; \% \mathrm{pa}$

o droplet boiling point, droplet temperature $\mathrm{DT}=311.7 ; \% \mathrm{~K}$

\% Saturation vapour pressure of water at droplet surface temperature Psat $=1000 * \exp (16.387-(3885.7 /((\mathrm{DT}-273)+230.17))) ; \% \mathrm{pa}$

\% medium temperature, assumed 5 degree above the boiling point $\mathrm{MT}=\mathrm{DT}+5 ; \quad \mathrm{K}$

응 droplet radius

for $i=1: 1: 3$ 


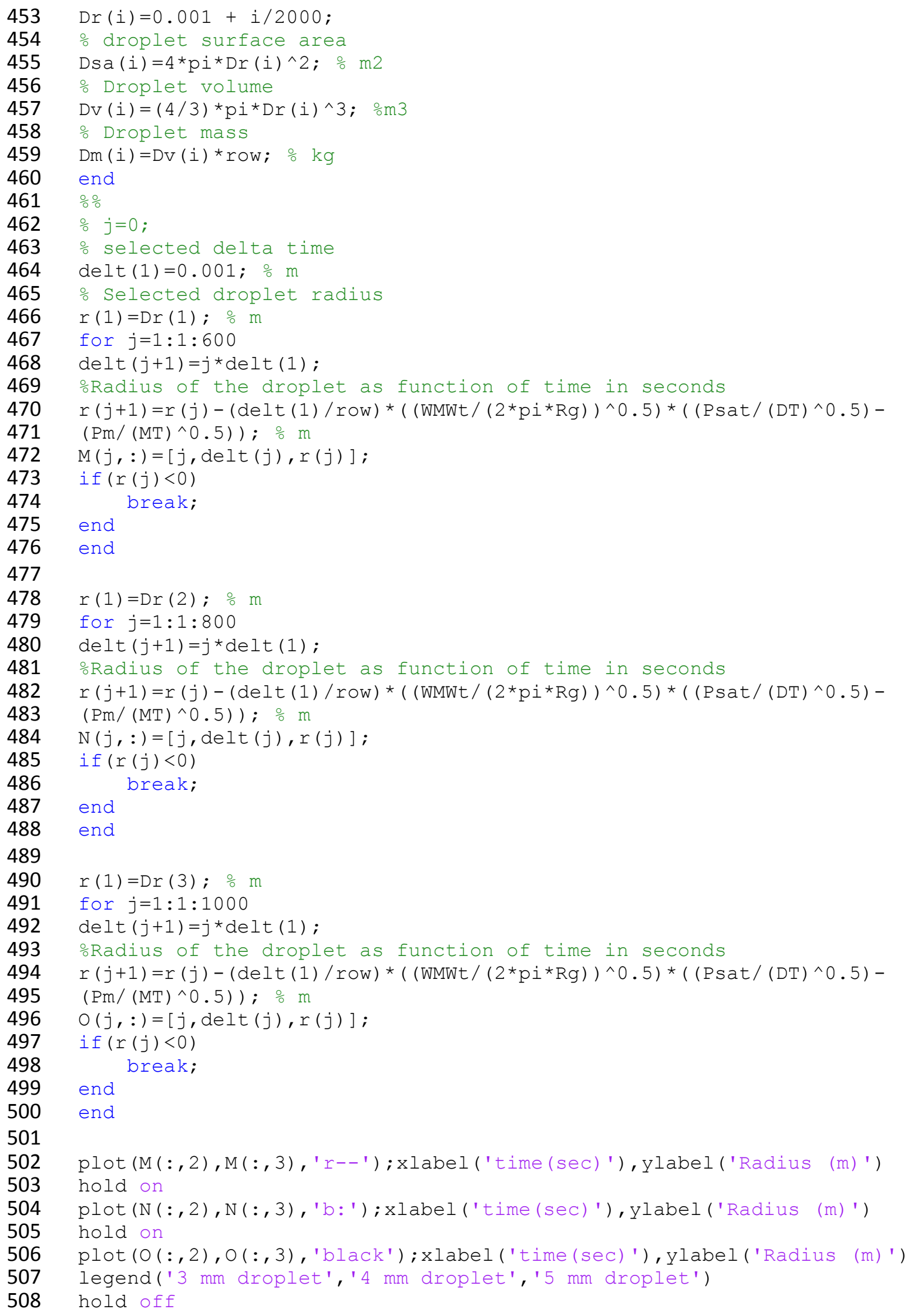


509

510 